\title{
LA NEGACIÓN DEL OTRO COMO OTRO ES INSIGNIFICANCIA EN ACCIÓN
}

\author{
The Denial of the Other as Other is Insignificance in Action
}

\author{
Rafael Miranda Redondo \\ (CICC, México)
}

\begin{abstract}
Resumen
En el artículo a continuación abordamos la recepción de la obra de Castoriadis en America Latina a través de un ejercicio de dialogo con uno de los autores del numero 11 de PROMETEICA, Emanuele Profumi. En particular nos ocupamos de ilustrar el contexto en el que dicha obra es recibida por los medios académicos y políticos en el continente gracias a los desarrollos de Castoriadis en torno al fenómeno descrito de aumento de la insignificancia, poniendo un énfasis particular en la noción de descomposición social en cuya base se encontraría la crisis de autoreferencia en la sociedad contemporánea. Para argumentar la relevancia de la noción de descomposición social hacemos uso de la manera como Castoriadis aborda la cuestión del proyecto social en occidente y de la manera como su ausencia tiene un efecto definitivo para la relación de occidente a nivel global y muy particularmente respecto al abismo que lo separa del mundo Árabe. Damos cuenta de todo ello teniendo delante los recientes atentados en Paris y el conflicto actual que involucra las potencias mundiales y el Estado Islámico.
\end{abstract}

\begin{abstract}
In the article below we address the reception of the work of Castoriadis in Latin America through an exercise in dialogue with one of the authors of the number 11 PROMETEICA, Emanuele Profumi. We are particularly interested in illustrating the context in which this work is received. In particular we want to show how Castoriadis thought is received by Latin American academic and political circles. We understand the context to be shadowed by the developments of Castoriadis around the phenomenon described of the increasing insignificance, with particular emphasis on the notion of social decomposition, on which one might find the crisis of self-reference, faced by contemporary society. To argue the relevance of social decomposition, we use the way in which Castoriadis addresses the issue of the social project in the West and how its absence has a definite effect on the relationships of the West at a global level. This is particularly relevant regarding the abyss that separates the West from the Arab world; a reflection that takes place in view of the recent bombings in Paris and the current conflict involving world powers and the Islamic State.
\end{abstract}




\section{¿Quiénes somos y desde donde hablamos?}

En el numero 11 de la revista argentina Prometeica ${ }^{29}$ hemos visto con gran alegría que - en importante medida gracias a la iniciativa de Emiliano Aldegani-, el pensamiento de Castoriadis ha sido motivo de la entrega. A lo largo de nuestra trayectoria para difundir la obra del autor en castellano hemos tenido el privilegio de participar en esfuerzos similares, en el año 2002 acompañamos y colaboramos para la edición del numero 54 de la revista española extinta Archipiélago, dedicado a Castoriadis. Durante las ultimas décadas, desde el sitio electrónico Cornelius Castoriadis/Agora International ${ }^{30}$, seguimos con entusiasmo la dedicación que revistas como la que anima en el espacio virtual la Fundación Andreu $\mathrm{Nin}^{31}$, asi como lo hicieran las -también extintas-, colombiana Ensayo y Error, argentina Zona Erógena y mexicana Vuelta para dar a conocer la obra monumental del filósofo y psicoanalista de origen greco-francés.

En este orden de cosas y por infortunio acostumbrado a la habitual indiferencia respecto al pensamiento de quien Edgar Morin denominara "un titán del espíritu”, en medios académicos y políticos latinoamericanos-, indiferencia de la que François Dosse se lamenta en la biografía de Castoriadis de reciente publicación (Dosse, 2014, p. 8), me propongo relanzar el debate en las líneas a continuación. Un debate, anticipo, no casualmente disimulado o de plano negado por dichos medios, justamente por la incapacidad de estos de asumir los desafíos que ese pensamiento plantea. En efecto la reivindicación, desde su relevancia política, del psicoanálisis y la crítica radical respecto a la teología racional que subyace al determinismo con el que la tradición filosófica heredada había renunciado a la razón de ser que está en su origen, la interrogación ilimitada, para refugiarse en el comentario, la simulación y con ello en la legitimación del hecho consumado, iba a hacer que las tradiciones del marxismo y del pensamiento posmoderno, incluyendo al post-estructuralismo y los denominados estudios poscoloniales -derivados de la antropología cultural, de su relativismo y de la teología de la liberación-, vieran el pensamiento de Castoriadis como una amenaza a sus fundamentos.

29http://www.prometeica.com/ojs/index.php/prometeica

30http://agorainternational.org/es/

31http://www.fundanin.org/acastoriadis.htm 
Hostilidad que se dirige a una propuesta de largo respiro, a su ontología -y respecto a lo que de ella deriva-, y que iba a interrogarse radicalmente en sus efectos respecto a los fundamentos de la cultura política tradicional del orbe hispanohablante y respecto a las ciencias sociales practicadas en esa región lingüística, no se hizo esperar. Astutamente, en particular los sectores de iglesia comprometidos en el continente y soterradamente dictadores de la cultura contestataria oficial, iban a recurrir para el descrédito a los viejos argumentos que han inspirado toda reacción de clausura en "lo propio", porque todo el mal viene de afuera. El recurso de la identidad como algo esencial, criterio obviamente manipulado según el destinatario del argumento retórico -Marx, Cristo y un numero importante de neo-teólogos serían latinoamericanos, sin saberlo-, iba a ocultar, con la indiferencia respecto al pensamiento castoridiano, bajo la simulación como cultura política, la apertura ante la alteridad radical que conlleva toda posibilidad real de autonomía.

Paralelamente y en un acto desafiante frente a esa insignificancia algunos sectores marginales en el continente, particularmente ligados al socialismo libertario y al anarquismo, iban a encontrar en la obra de Castoriadis una fuente consistente de inspiración. Un dialogo todavía insipiente entre estos sectores y los sectores que en el viejo continente habían librado la tentación de la burocratización, del tercermundismo mesiánico, de las ideas débiles y/o del pensamiento posmoderno, reivindicando la nobleza de la política y negándose a asimilarla a la fuente de todo totalitarismo, se ha venido desarrollando en torno a la obra castoridiana, precisamente. Un dialogo inspirado del cosmopolitismo y del internacionalismo, que no ha sucumbido al poder seductor de las identidades y los comunitarismos, poniendo sobre la mesa la consigna, de venerable ancianidad, según la cual la filosofía y la filosofía que subyace a toda ciencia que se reivindique como tal, unicamente se realiza a medias en el decir y solo encuentra la razón última de su existencia en el hacer.

Una subjetividad reflexiva y deliberante en boca de un colectivo anónimo, que no posee una teoría total sino que se enfrenta a la alteridad no sabiendo, o sabiendo muy poco, del lugar a donde se dirige y que es como Castoriadis va a entender el proceso de transformación radical de la sociedad. Un colectivo anónimo, en calidad de instancia operante de manera latente en la autoconstitución de toda sociedad y cuyo registro explicito, en nuestro continente -por razones que hemos mencionado respecto, en 
particular, a las profundas raíces católicas de la cultura política continental-, sigue siendo una asignatura pendiente.

\section{El ejercicio de doxai}

Los contenidos esquemáticos en líneas anteriores están en el origen del ejercicio a continuación. En efecto un esfuerzo importante, en el sentido de asumir la asignatura pendiente mencionada, ${ }^{32}$ creo que tiene que ver con dialogar con aquellos sectores que, en otros países y de manera particular en Europa mediterránea -también de tradición católica-, han asumido el desafío de hacer una crítica radical del marxismo -no solo como ideología de la burocracia-, de la cultura militante en sentido tradicional y de las ilusiones del discurso identitario, desde Castoriadis.

En el mismo numero de Prometeica citado encontré diversos artículos que podrían servir para retomar dicho dialogo, en particular me interesé en el artículo de Emanuele Profumi (2015) que se propone mirar críticamente la cuestión del declive de la autorepresentación que, según el autor es formulado por Castoriadis. En la perspectiva de Profumi $(2015,73)$ es necesario, teniendo presente còmo Castoriadis piensa la sociedad contemporanea, "rechazar la idea de descomposición y elaborar una critica del presente." Esa tarea deberá ser asumida a partir del proyecto de autonomía pensando en la naturaleza de una "nueva forma de dominación" que estaría emergiendo en las sociedades occidentales bifurcadas en donde se oponen democracia y capitalismo, bifurcación que se va a manifestar a través de la alternativa entre la servil y activa defensa del statu quo y una práctica por la autonomía.

El autor va a abordar la cuestión explicando cómo Castoriadis entiende la descomposición social, la cuestión de la insignificancia y el conformismo. Una vez expuestos esos contenidos desde la manera como él lee a Castoriadis, Profumi se va a avocar a argumentar porqué, a su entender, no estaríamos ante una descomposición de la sociedad y sí ante la creación de una nueva sociedad hetrónoma en la que prevalece la servidumbre voluntaria. Una reflexión sobre crisis y polarización, haciendo uso de recursos puestos a disposición por autores como el filósofo Daniel Bensaid y el

32En otros campos mas del hacer hemos emprendido desde hace años lo que corresponde, ver en particular la obra institucional desde el portal de Agora International y la creación de la Cátedra Interinstitucional Cornelius Castoriadis. (Para mayores detalles ver Miranda, 2014) 
psicoanalista Christophe Dejours, va a permitir a Profumi cerrar su texto dejando abierta la interrogante respecto a los alcances en la materialización de ese debate de los movimientos sociales internacionales.

\section{La institución que nos habita}

La cuestión en particular de la descomposición social como la entiende Castoriadis (1982, p. 12) me parece que es en efecto un punto fundamental en el análisis de la sociedad contemporánea. Los recientes acontecimientos en Paris, protagonizados, no por "extranjeros", sino por ciudadanos (Benslama, 2015) franceses y belgas en su mayoría provenientes de la inmigración y la manera como se está perfilando lo que algunos han llamado la tercera guerra mundial, con los bombardeos sobre los territorios controlados por el Estado Islámico, nos ofrecen un campo de análisis fértil para poner a prueba el alcance de dicha categoría.

En el texto citado Castoriadis va a abordar la cuestión de la categoría de la descomposición social vinculándola con un fenómeno que concierne a "todas las clases". Dicha descomposición tendría lugar en un contexto -el de los países capitalistas desarrollados-, que había evolucionado del estado de bienestar y de expansión a la alza acelerada de los precios y al aumento grave del desempleo. A dicho proceso iba a corresponde la pauperización de los medios dirigentes y los devastadores efectos de la economía en los campos energético, de recursos naturales, del medio ambiente y de la ecología.

Ahora bien la esfera en donde dicha descomposición, analizada por Castoriadis, nos parece que tiene la mayor relevancia es aquella que se refiere a un proceso -minado por la despolitización y la privatización de la vida, tendencias paralelas a la burocratización en general pero en particular a la de los "aparatos" políticos y al acaparamiento de la toma de decisiones en lo fundamental por los lobbies de todo tipo-, de derrumbe de la autorepresentación de la sociedad. Cito:

(...) que hay crisis de significaciones imaginarias sociales, que estas ya no brindan mas a los individuos las normas, los valores, los referentes, las motivaciones que les permiten a la vez hacer funcionar la sociedad y mantenerse ellos mismos, mal que bien, en un equilibrio vivible ( el "malestar banal" que Freud oponía a la "miseria neurótica”) (Trad. RM) (1982 p. 21) 
Los efectos de esa crisis serán de proporción en la medida en que todo individuo debe ser portador de la representación de sí de la sociedad a la que pertenece. Autorepresentación que permite al individuo cubrir para sí mismo el abismo psíquico sobre el cual él vive. Dicha crisis de autorepresentación va a manifestarse en la sociedad occidental contemporánea como una incapacidad de responder a las grandes interrogantes que están en su origen: ¿quiénes somos? ¿para qué somos? ¿qué queremos?. Entonces procede preguntarse con Castoriadis: el hombre contemporáneo ¿quiere la sociedad en la que vive? o ¿quiere otra? ¿quiere una sociedad en general?. La lectura de los actos conduce a suscribir lo que el autor señala "El hombre contemporáneo se comporta como si la existencia en sociedad fuera una odiosa faena, que solamente una desafortunada fatalidad le impide esquivar." (1982, p. 22) (Trad. RM)

La manera como dicha crisis de autorepresentación va a precipitarse en el campo de la educación y la cultura debe ser analizada y asumida en sus implicaciones. Lo que está aquí en juego es precisamente la fabricación del tipo antropológico que la sociedad occidental es capaz o no de formar para su funcionamiento continuo. Los procesos por los que tiene lugar dicha fabricación son puestos en práctica por instituciones, como la familia y la educación, que se encuentran igualmente en crisis. La desintegración de los roles tradicionales -mujer, hombre, padres, hijos, maestro, alumno- , desintegración en efecto expresa el empuje de los individuos hacia la autonomía, tiene, en la sociedad contemporánea, efectos ambiguos. La crisis de la relación educativa tampoco logra en la contemporaneidad materializarse en formas consistentes de ejercer dicho proceso, de manera alternativa.

El joven individuo "en ausencia de religión, de ideas "políticas", ni de solidaridad social con una comunidad local o de trabajo con sus "camaradas de clase". Si él no se marginaliza (droga, delincuencia, inestabilidad "caracterial") le queda la vía real de la privatización...” (1982, p. 19) (Trad. RM) Mientras que el credencialismo -de búsqueda desaforada de títulos-, va viento en popa, tanto alumnos como maestros manifiestan en sus acciones un total desinterés por lo que realmente ocurre en las escuelas. A lo anterior se suma el hecho de que ese proceso de privatización va a corresponder a la confrontación del joven educando con una sociedad en la cual los valores y las normas son substituidas por la valorización del "nivel de vida", del "bienestar" y del consumo. Paralelamente, en el campo mas propiamente del conocimiento formal, el comentario y la interpretación van a ser el 
substituto del pensamiento creador.

La medida en que la situación descrita, como entiende Castoriadis un proceso de descomposición social, ilustra el contexto de los recientes atentados en Paris y -mas en general-, la ausencia de un proyecto social en el occidente moderno, proyecto eventualmente significado por quienes son parte de esa sociedad, me parece que no debe ser objeto de negligencia. A la anterior exigencia es claro que deben añadirse las implicaciones que conlleva un proyecto, parcialmente fracasado, dirigido a la incorporación de las poblaciones migrantes en las sociedades de destino. Los relativismos culturales y la retórica de la diferencia tan socorridos por el pensamiento posmoderno y la antropología culturalista, algo tienen de responsabilidad en todo ello, me ocupo en otros espacios ( Miranda, 2014, 27)

\section{¿Hay una alternativa al binomio xenofobia/angelismo?}

La relevancia de la responsabilidad mencionada para la coyuntura actual hace que merezcan la pena algunos párrafos adicionales dedicados a proyectar lo dicho al plano global de las relaciones norte-sur y muy particularmente respecto al mundo árabe no solo el que subsiste en los territorios de las antiguas potencias coloniales como lo son algunos países de Europa Occidental.

En la entrevista de Castoriadis con Edgar Morin (1991) Castoriadis aborda la cuestión con una agudeza anticipatoria que es digna de admiración. Para introducir la problemática el autor habla de la Guerra del Golfo como el evento que en la historia moderna corre el riesgo de ensanchar el abismo cultural, social, político e imaginario que existe entre los países occidentales y el mundo árabe. Un abismo cultural que entre otras muchas situaciones específicas debe ser valorado a la luz del conflicto en medio oriente y la cuestión kurda por decir lo menos.

En la relación entre el mundo islámico y el occidente un elemento fundamental es compartido. Mientras que la descomposición social descrita para este último en líneas anteriores se manifiesta por la crisis de la autoreferencia, para el caso del mundo islámico -ver por ejemplo la primavera árabe- es la observancia meticulosa de la tradición la que, en algunos sectores radicales va a dar cuenta del proceso de descomposición social. La repetición institucional que conlleva toda religión monoteísta -repetición en el plano de lo 
manifiesto solamente-, para el caso del mundo árabe, de su particular resistencia a desvincular lo religioso de lo político -en esas sociedades el código penal es el Coran- salvo raras excepciones, se va a manifestar por la vía de una "formidable mitologización de los árabes por ellos mismos que se presentan como eternamente victimas de la historia.” (1991, p. 53).

Esta mitologización ignora por supuesto el hecho de que si hubo en la historia del mediterráneo una potencia conquistadora, esa fue precisamente protagonizada por los árabes en los siglos VII al XI. De Arabia a Egipto posteriormente conquistados por los turcos del imperio Otomano, la región ha sido quizás el ejemplo mas significativo ${ }^{33}$ de la conversión forzada de las poblaciones sometidas. Realidad hecha posible y persistente en la actualidad, en un plano político, gracias a estructuras de poder arcaicas o a la mezcla de arcaísmo y estalinismo en algunos casos. Esas sociedades, en palabras de Castoriadis, habrían tomado lo peor de occidente para montarlo sobre sociedades culturalmente religiosas (1991, p. 53). El autor va a vaticinar, en ese mismo texto, que en caso de que caiga Sadam Husein (el texto es de 1991), lo mas seguro es que ese sería remplazado por un régimen fundamentalista chiita.

La mentalidad mencionada y que se inspira de la mitologización continua y se refuerza ante una modernidad -en donde se concentran siglos de luchas para separar lo religioso de lo político-, va a encontrarse frente a un occidente que ha dejado de crear significaciones emancipatorias. La posibilidad de la democracia en el mundo árabeislámico está cancelada en principio debido a que éste no ha logrado llevar a cabo la laicización. No obstante los árabes, nos dice Castoriadis (1991, p. 57), estuvieron mas civilizados que los occidentales por un largo período -periodo al termino del cual esa condición se esfumó-, lo que esos pueblos recuperaron de la antigüedad nunca fue de orden político. Lo mismo vale para los países arabe-islámicos en donde hubo intentos importantes en ese sentido, mas orientados por la "revolución nacionalista" que incluía también la emancipación respecto a occidente, que por el proyecto de la sociedad autónoma propiamente. Una "revolución nacionalista" - ver el mesianismo de Fanon y de Sartre respecto a la Guerra de Argelia- que, como para el caso de la revolución “comunista”, eran, de hecho, promesas religiosas.

33Ver igualmente con los años la ex -órbita soviética. 
El balance del autor no tiene pliegues la resistencia a la amenaza de la identidad (Miranda, 2006), cuando ya no hay futuro emancipador y el presente está enfermo, va a recurrir a lo único que queda, que es el pasado. Un pasado vivido mitológicamente y que, por lo tanto, va a fortalecer el empuje fundamentalista. Irónicamente la crisis de la modernidad va a impulsar el fundamentalismo, nos dice Castoriadis (1991, p. 55). El proyecto de autonomía -esa creación europea que es todavía defendible y que inspiró la mejor modernidad-, no es el paraíso en la tierra -ni mesiánico ni apocalíptico-, algo dice de hacia donde queremos ir, es esto sin embrago lo que hace falta al occidente moderno.

\section{El por ser es lo que más necesita de nosotros}

En líneas anteriores hemos ilustrado la manera como Castoriadis va a entender el proceso de descomposición social del occidente moderno, lo hemos hecho sirviéndonos de la notoriedad de dicho proceso a la luz de los últimos acontecimientos en Paris y mas en general respecto a la relación de occidente con el mundo árabe. Para cerrar este escrito quiero regresar al texto de Profumi y dejar anotadas algunas líneas de dialogo que espero susciten el interés de los lectores. Algunos pasajes del texto de Profumi tienen el merito de recordarnos la manera como la sociedad occidental contemporánea ha dejado de quererse como sociedad. Ese proceso que en Castoriadis va a manifestarse por la vía de la crisis del sentido evocada, para Profumi tiene que ver con la dicotomía excluyente entre democracia y capitalismo. Dicha dicotomía tendría su traducción al nivel del posicionamiento político gracias a la oposición excluyente entre la defensa servil y activa del estatus quo y la praxis de la autonomía. Es así como la modernidad que conocemos sería el resultado de la prevalescencia de la lógica del poder y de las organizaciones capitalistas.

Sabemos desde que hemos hecho una lectura atenta de los textos de Castoriadis correspondientes al periodo de Socialisme ou barbarie, que el capitalismo no necesita el conformismo de los trabajadores sino precisamente su resistencia a la explotación para sobrevivir. A lo anterior se suma lo que Castoriadis agrega de pasada pero que en otros lugares de su obra tiene gran relevancia ${ }^{34} \mathrm{y}$ es el hecho de que la relación parcialmente alienante respecto al capital que viven los trabajadores, también la viven, aunque en otro terreno, los propietarios de los medios de producción. Lo anterior nos lleva de lleno a la

34En conversación con Daniel Blanchard, sabemos que este fue un punto de tensión al interior del propio grupo $S$ ou B. 
cuestión de la interiorización de la norma como un punto central respecto a los procesos de sentido que acompañan las realidades del mundo contemporáneo, en la fábrica pero también el la familia, el barrio, la organización, el partido o la congregación religiosa, para mencionar algunos.

El alejamiento de la concepción de las relaciones sociales como procesos objetivos y conscientes, alejamiento que paulatinamente fue acompañando la reflexión no solo al interior del grupo S ou B sino mas en general respecto a lo que quedó de cultura política crítica en los márgenes del pensamiento posmoderno en occidente, tiene aquí una relevancia crucial. Ese alejamiento permitió a Castoriadis y su grupo no solo entender el fenómeno burocrático sino también -de relevancia fundamental en particular para las dictaduras de izquierda en America Latina- la posibilidad de no asimilar las relaciones de producción a las formas de propiedad.

En el proceso de interiorización de la norma Castoriadis va a fundar las posibilidades de una relación distinta con la institución propia. Ahí en donde la propia institución va a ser asumida como un nomos, es decir como algo que nosotros hemos creado y que, si no nos conviene mas, podemos explícitamente cambiar, estaremos ante el proyecto en curso de la sociedad autónoma. Diferentemente ahí en donde la institución que esta en nuestro origen es concebida por nosotros como siendo parte de la phycis y por lo tanto ahí en donde la relación con dicha institución es del orden de lo mítico, estaremos ante el proceso de consolidación de la sociedad heterónoma o de repetición. Estas dos posibilidades conllevan implícitamente una manera de posicionarse ante la alteridad y la alteridad que nos habita. Es la apertura -cuidado no la aceptación a priori- de la alteridad como alteridad -no como diferencia o como variación del uno- lo que va a fundar la posibilidad de la sociedad autónoma. La creación -ni buena ni mala per se- acompaña los procesos de autoconstitución de lo social. En unos casos eso es vivido como una promesa, en otros es ocultado porque se considera una amenaza para la propia identidad.

Volviendo a la descomposición social a la que Profumi se resiste a asimilar lo que él identifica como la emergencia de una nueva heteronomía arguyendo que esa descomposición es inadmisible a nivel lógico e histórico, es claro que la lógica a la que se hace alusión es una lógica heredada en donde la heteronomía sería el resultado de la acción consciente, cínica, de unos en demerito de otros. La servidumbre voluntaria a la que Profumi recurre para argumentar respecto a lo inaceptable de la noción de 
descomposición, es claro que remite a los procesos conscientes dejando de lado aquellos procesos inconscientes en los que la institución propia es objeto de transferencia. En este contexto la manera como el tipo antropológico de la sociedad occidental contemporánea enfrenta a la propia institución, una vez que se ha librado de las obligaciones impuestas por la verdad revelada, es de por si singular. A diferencia de lo que ocurre en la gran mayoría de las sociedades históricas conocidas, en el caso de la sociedad autónoma en proyecto -cuya significación imaginaria social de la autonomía sobrevive marginalmente en los espacios no manifiestos de la sociedad contemporánea-, la descomposición radica mas que en una voluntad de servidumbre en una imposibilidad de formular aquello que nos libra de la pura repetición institucional. La sociedad se descompone porque renuncia explícitamente a ser sociedad limitándose a la repetición institucional o a lo que, en contextos de América Latina he denominado la cultura de la simulación (Miranda Ayotzi). Donde hay repetición hay ausencia de sentido nuevo.

La huida de la libertad que Profumi menciona nos remite igualmente a algunos callejones sin salida. De entrada presumimos que el autor no esta, con esa aseveración, hablando de que hay una libertad en el origen. Sabemos -Castoriadis no se cansa de repetirlo-, que la libertad y la autonomía son creaciones y que en tanto tales son significaciones imaginarias sociales, valores positivos o negativos según la sociedad de que se trate que, precisamente, y que no son universales. Ocultamiento de la alteridad, que tiene lugar de manera extrema en el caso de la sociedad de repetición, cuya manifestación mas flagrante es la sociedad religiosa y que, en el caso de la sociedad autónoma en proyecto, representa el desafío a superar por la vía de la explicitación. Esta explicitación de la transferencia respecto a la institución propia, no obstante representa un cometido de la sociedad autónoma en proyecto en sus orígenes hoy se encuentra en una situación de impasse.

La cultura del consumo, los fanatismos religiosos, la insignificancia son algunas de las modalidades en que hoy en occidente se manifiesta el problema del vacío de sentido. Esas maneras particulares de ocultar la alteridad, maneras cuya realidad en el occidente que conocemos es masiva, es un rasgo de descomposición social en la medida en que tenemos a la vista el por ser de la sociedad, es decir la dimensión por la cual la sociedad se asume como tal. El otro registro, el de la heteronomía, cuya realidad es igualmente masiva, nos remite -quizás aquí el mayor diferendo con Profumi-, únicamente al ser ahí de la 
sociedad contemporánea. Negar el conflicto y con ello la política, que equivale en clave marxista y/o decolonial y/o pastoral ascendentes, al anticapitalismo a secas, en nombre de una teoría total y de un lugar en donde no existirá la separación -el comunismo, la identidad perdida o el reino de dios-, nos remite precisamente a la dimensión de la sociedad que hoy tenemos delante. La sociedad que será cuando esta deje de estar, ese es otro cantar.

\section{Bibliografía}

Benslama, F. (2015) «Pour les désespérés, l'islamisme radical est un produit excitant » (Entrevista realizada antes de los atentados en Paris y Saint Denis) viernes 13 noviembre 2015, Le Monde http://www.lemonde.fr/societe/article/2015/11/12/pour-les-desesperes-lislamisme-radical-est-un-produit-excitant $4808430 \quad 3224 . h$ tml

Castoriadis, C. (1996) "La crise des sociétés occidentales". Politique internationale, 15 (printemps 1982): 131-47. En La Montée de l'insignifiance. Les carrefours du labyrinthe IV. Paris: Éditions du Seuil, 1996. 245pp.

(1996) "Entre le vide occidental et le mythe arabe" ("Discussion avec Edgar Morin"). Le Monde, 19 mars 1991: 2. En La Montée de l'insignifiance. Les carrefours du labyrinthe IV. Paris: Éditions du Seuil, 1996. 245pp.

Dosse, F. (2014) Castoriadis. Une vie. Paris: Éditions La Découverte, 2014.

Miranda, R. (2014) "De la intervención sociaonalítica a la obra institucional por la autonomía. El caso de la Cátedra Interinstitucional Cornelius Castoriadis". En coautoría con Roberto Manero. En Tarántula. Institución y hacer pensante por la autonomía. Castoriadis en la trama latinoamericana entre academia y política. Rafael Miranda Redondo, Dolores Camacho Velázquez y Jorge Alonso (Coordinadores). Ediciones de la Casa Chata. Centro de Investigaciones y Estudios Superiores en Antropología Social. México DF. ISBN 978-607-486-2706.

(2013) Estado del proyecto de autonomía y esencialización de lo identitario. Notas sobre America latina desde Castoriadis. Por Rafael Miranda Redondo. http://www.pueblosyfronteras.unam.mx/v8n16/pdfs/art 01.pdf En Pueblos y Fronteras. La lucha por la autonomía: prácticas y proyectos en movimientos sociales latinoamericanos. Coordinadora del Numero: Dolores Camacho Velazquez. Publicación digital semestral Vol. 8, Num. 16. Diciembre 2013-Mayo 2014. PROIMMSE-IIA-UNAM.

México. (http://www.pueblosyfronteras.unam.mx/) 
(2006) Las Fronteras del odio. Reflexión sobre la alteridad a partir de Cornelius Castoriadis. Por Rafael Miranda. En revista Tramas. Subjetividad y procesos sociales. UAM-X. México. 2006. http://tramas.xoc.uam.mx/tabla contenido.php?id fasciculo=65 | http://www.fundanin.org/miranda1.htm

Profumi, E. (2015) ¿Servilismo o autonomía? El proyecto de autonomía frente a la nueva heteronomía. Profumi (EHESS-CESPRA, Francia) Traducción del francés de E. Aldegani. Prometeica. Año V. Num. 11. Invierno 2015. ISSN 1852-9488. Argentina. 